\title{
Radiofrequency versus ultrasonic energy in laparoscopic colorectal surgery: a metaanalysis of operative time and blood loss
}

\author{
Nicola Di Lorenzo $\cdot$ Luana Franceschilli • \\ Marco Ettore Allaix · Anastasios Asimakopoulos • \\ Pierpaolo Sileri $\cdot$ Achille L. Gaspari
}

Received: 26 November 2011 / Accepted: 26 March 2012/Published online: 12 May 2012

(C) Springer Science+Business Media, LLC 2012

\begin{abstract}
Background Various energy sources are available for tissue dissection and vessel sealing in laparoscopic colorectal surgery. The electrothermal bipolar vessel sealing system (EBVS) and ultrasonic energy (UE) devices are widely used to provide hemostatic dissection in laparoscopic procedures. Nevertheless, available evidencedbased data comparing their operative results still are scarce. This study conducted a metaanalysis of controlled clinical trials comparing EBVS and UE in terms of operative time and intraoperative blood losses in laparoscopic colorectal surgery

Methods The MEDLINE and Embase databases were searched using medical subject headings and free text words. All randomized controlled trials (RCTs) and controlled clinical trials using EBVS and UE in laparoscopic colorectal surgery were considered for inclusion in the
\end{abstract}

N. D. Lorenzo · L. Franceschilli $(\bowtie) \cdot$ P. Sileri · A. L. Gaspari Department of Surgical Sciences, University of Rome Tor Vergata, Policlinico Tor Vergata, Viale Oxford 81, 00133 Rome, Italy

e-mail: luana.franceschilli@virgilio.it

N. D. Lorenzo

e-mail: Nicola.di.lorenzo@uniroma2.it

N. D. Lorenzo - L. Franceschilli · M. E. Allaix ·

A. Asimakopoulos · P. Sileri - A. L. Gaspari

Biotechnologies and Techniques Applied to Surgical Sciences, University of Rome, Tor Vergata, Italy

M. E. Allaix

Department of Digestive Surgery and Centre for Minimally Invasive Surgery, University of Turin, Turin, Italy

A. Asimakopoulos

Division of Urology, Department of Surgical Sciences,

University of Rome, Tor Vergata, Italy study. Random effects models were used in case of heterogeneity to obtain summary statistics for the overall difference in operating time and blood loss between instruments.

Results Four studies comparing EBVS with UE for 397 patients (200 EBVS vs. 197 UE patients) were included in the study. The findings showed that EBVS was associated with a significantly shorter operative time and less intraoperative blood loss than UE $(p<0.05)$.

Conclusions The metaanalysis indicated that EBVS is associated with a shorter operative time and less blood loss than UE in laparoscopic colorectal surgery. However, these results should be interpreted with caution due to the high heterogeneity of the included trials and the limited number of studies with a high level of evidence. More adequately designed RCTs with a larger number of patients are required to confirm the results of this metaanalysis.

Keywords Instruments $\cdot$ Technical $\cdot$ Dissection

Laparoscopy in colorectal surgery has gained wide acceptance for both benign [1] and malignant lesions [2, 3]. Tissue dissection, coagulation, and division of the mesocolon and mesorectum may present technical and hemostatic challenges [4]. Cases of severe inflammation as observed in acute diverticulitis or inflammatory bowel disease or even the presence of a fatty mesocolon/mesorectum may hinder dissection and hemostasis [5].

Conventional mono- and bipolar electrosurgery presents some shortcomings in this type of surgery, including the risk of thermal injury, difficult hemostasis, and smoke production, necessitating the use of additional tools such as bipolar graspers, sutures, and clips [6, 7]. The search for a safer and quicker energy source has resulted in the 
development of several multifunctional tools. In this field, two different technologies are commonly used for this surgery: electrothermal bipolar vessel sealing (EBVS) [8] and ultrasound energy (UE) [9-11]. Instruments for both technologies are used in both laparoscopic and open procedures over a range of surgical specialties including gynecologic, colorectal, urologic, and general surgery. These devices often are used in the effort to reduce operating time and complications.

Both EBVS and UE currently are used in laparoscopic surgery, and several studies have demonstrated their advantages for different abdominal procedures [12-16]. However, few clinical studies have compared the two instruments. Consequently, no definitive evidence is available regarding the superiority of one instrument over the other in terms of dissection times and hemostatic properties. The necessity of this evidence is becoming louder in the current era of the global economic crisis, in which an operating benefit (e.g., reduced surgical time or blood loss) is necessary for the health system to incur the extra cost of the novel instruments.

To appraise the quality of evidence available in the literature and to provide insightful clinical information for assistance in the decision-making process, we undertook a systematic review and metaanalysis of the literature to compare the effectiveness of EBVS and UE surgical devices in terms of operative time and intraoperative blood loss during laparoscopic colorectal surgery.

\section{Materials and methods}

Following the Preferred Reporting Items for Meta-Analysis (PRISMA) statement [17], we performed a systematic review of all published randomized controlled trials (RCTs) and controlled clinical trials regarding EBVS and UE. Our search was performed using the National Library of Medicine's MEDLINE and Cochrane Central Register of Controlled Trials (CENTRAL) from 1990 to June 2011. Searches were carried out using medical subject headings (MeSH) and free text words. The keywords adapted for each database search were "randomized" OR "comparative" AND "laparoscopy" AND "colorectal" AND "outcome" OR "operative time" OR "blood loss" AND "hemostasis" AND "dissection" AND "harmonic scalpel" OR "Ultracision" AND "LigaSure" OR "bipolar electrosealing device" OR "bipolar electrosurgery" OR "bipolar vessel sealing system" OR "EBVS" OR "electrothermal bipolar coagulation" OR "electrothermal bipolar vessel sealer" OR "electrothermal bipolar vessel sealing" OR "EBVS system" OR "electrothermal vessel sealing" OR "energized vessel sealing" OR "energy-based vessel ligation" OR " LigaSure coagulating system" OR “ LigaSure radiofrequency coagulator" OR "LigaSure vessel sealing device" OR "LigaSure vessel sealing system" OR "vessel sealing" OR "vessel sealer."

The patients included in the study were adults affected by either benign or malignant colorectal diseases who underwent elective laparoscopic colorectal resections. Locally advanced malignant disease, previous bowel surgery, and pregnancy were the main exclusion criteria for patient enrollment in the considered studies Fig. 1.

Only full original clinical articles from peer-reviewed journals were included to provide adequate details on patient selection, allocation, study design, outcome, and measurement methods. This procedure led to an accurate, unbiased assessment and comparison of the study results. Reference lists from the included articles were manually checked, and additional studies were included when appropriate.

A total of 111 papers concerning EBVS and UE were identified. Two authors (A. D. A. and M. E. A.) independently screened the titles and abstracts of each citation and recorded the data on a standardized data extraction form that included surgical procedure, description of withdrawal, masking, primary end point, other end points, whether a power analysis was performed, and sample size. Differences between the two reviewers were resolved by reexamination of the original article until consensus was attained about the study's data.

\begin{tabular}{|c|c|c|c|c|c|c|c|}
\hline Author & Study design & Ligasure & Ultracision & Clip & Monopolar energy & Operating time & Blood loss \\
\hline Morino & RCT & & 74 & & $\mathbf{7 2}$ & $92.96(45-170)$ vs $102.55(75-190)$ & $140.8(35-290)$ vs $182.6(50-330)$ \\
\hline Campagnacci & retrospective & 32 & 37 & & & $111(70-195)$ vs $133(95-190)$ & $115(30-160)$ vs $370(150-680)$ \\
\hline Campagnacci II & retrospective & 50 & 47 & & & $140(120-170)$ vs $176(95-240)$ & $150(70-220)$ vs $455(270-845)$ \\
\hline Campagnacci III & retrospective & 18 & 16 & & & $153(130-220)$ vs $201(145-320)$ & $185(100-285)$ vs $495(280-900)$ \\
\hline Hubner & RCT & 21 & 20 & & 20 & $105(58-195)$ vs $90(45-177)$ vs $137(65-230)$ & $50(0-600)$ vs $50(0-500)$ vs $125(0-450)$ \\
\hline Takada & prospective & 8 & 8 & & & $7.9 \pm 0.9$ vs $18.4 \pm 0.7$ & \\
\hline Takada II & prospective & 7 & 7 & & & $15 \pm 0.9$ vs $27.6 \pm 1.7$ & \\
\hline Rimonda & RCT & 70 & 70 & & & $116.3 \pm 44$ vs $114.8 \pm 47.6$ & $111.2 \pm 51.5$ vs $107.9 \pm 42$ \\
\hline Marcello & RCT & 52 & & 48 & & $177 \pm 62$ vs $186 \pm 70$ & $217 \pm 167$ vs $231 \pm 166$ \\
\hline Targarona & RCT & 15 & 12 & & 11 & $10(70-210)$ vs $120(65-220)$ vs $180(90-210)$ & $100(0-450)$ vs $100(0-150)$ vs $200(0-350)$ \\
\hline Heili & retrospective & & 49 & & 36 & 170 vs 187 & 98 vs 95 \\
\hline
\end{tabular}

Fig. 1 All studies comparing LigaSure and Ultracision energy 
This process yielded five papers [18-22] comparing the efficacy of EBVS and UE in terms of operative time and intraoperative blood loss in laparoscopic colorectal surgery. All the studies were read in their entirety to assess their appropriateness for inclusion in the metaanalysis. All studies that compared EBVS and UE in an experimental setting [23], EBVS/UE with other energy sources [24, 25], or two instruments for dissection and vessel sealing [26] in laparoscopic colorectal surgery were included in the metaanalysis.

\section{Statistical analysis}

The metaanalysis was conducted using the STATA 10.1 software. Random effects models were used in case of heterogeneity to obtain summary statistics for the overall difference in operating time and blood loss between instruments. The standardized mean difference (SMD) was calculated (with $95 \%$ confidence intervals) because this parameter standardizes the outcome for each individual study to the effect size found in terms of the standard deviation observed (in the study). Generally, SMD is the method used to pool data from different scales. Statistical heterogeneity was tested using the $\chi^{2}$ and the $\left(\mathrm{I}^{2}\right)$. The $\mathrm{I}^{2}$ describes the rate of variation across studies because of heterogeneity rather than chance, and ranges from 0 (no heterogeneity) to 100 (maximum heterogeneity). All results are reported with $95 \%$ confidence intervals $(95 \% \mathrm{CI})$, and all $p$ values are two-tailed.

\section{Results}

Characteristics of the trials

Five studies [18-22] comparing EBVS with UE and fulfilling the inclusion criteria were identified (Table 1). The trial of Hubner et al. [20] was excluded from the final analysis because it provided inadequate data for statistical analysis.

As reported in Table 1, only two studies [21, 22] were RCTs, whereas one study [19] was prospective and not randomized, and one study [18] was retrospective. Moreover, two studies reported intraoperative data with statistical analysis based on the surgical procedure performed. Therefore, we divided the patients of Campagnacci et al. [20] into Campagnacci (right hemicolectomies), Campagnacci 1 (left hemicolectomies), and Campagnacci 2 (anterior resection) groups, respectively. Similarly, the patients of Takada et al. [19] were divided in Takada (transverse colectomy) and Takada 2 (sigmoidectomy) groups.

Table 1 Details of studies

\begin{tabular}{|c|c|c|c|c|c|c|c|}
\hline Author & Study design & LigaSure & Ultracision & Clip & $\begin{array}{l}\text { Monopolar } \\
\text { energy }(n)\end{array}$ & Operating time $\min$ (range) & Blood loss $\mathrm{ml}$ (range) \\
\hline Morino et al. [24] & RCT & & 74 & & 72 & $\begin{array}{r}92.96(45-170) \text { vs } \\
102.55(75-190)\end{array}$ & $\begin{array}{c}140.8(35-290) \text { vs } \\
182.6(50-330)\end{array}$ \\
\hline Campagnacci et al. [18] & Retrospective & 32 & 37 & & & $\begin{array}{l}111(70-195) \text { vs } 133 \\
(95-190)\end{array}$ & $\begin{array}{l}115(30-160) \text { vs } 370 \\
(150-680)\end{array}$ \\
\hline Campagnacci 2 & Retrospective & 50 & 47 & & & $\begin{array}{l}140(120-170) \text { vs } \\
176(95-240)\end{array}$ & $\begin{array}{l}150(70-220) \text { vs } 455 \\
(270-845)\end{array}$ \\
\hline Campagnacci 3 & Retrospective & 18 & 16 & & & $\begin{array}{l}153(130-220) \text { vs } \\
201(145-320)\end{array}$ & $\begin{array}{l}185(100-285) \text { vs } 495 \\
\quad(280-900)\end{array}$ \\
\hline Hubner et al. [20] & RCT & 21 & 20 & & 20 & $\begin{array}{l}105(58-195) \text { vs } 90 \\
(45-177) \text { vs } 137 \\
(65-230)\end{array}$ & $\begin{array}{l}50(0-600) \text { vs } 50 \\
(0-500) \text { vs } 125 \\
(0-450)\end{array}$ \\
\hline Takada et al. [19] & Prospective & 8 & 8 & & & $\begin{array}{r}7.9 \pm 0.9 \text { vs } \\
18.4 \pm 0.7\end{array}$ & \\
\hline Takada 2 & Prospective & 7 & 7 & & & $\begin{array}{r}15 \pm 0.9 \text { vs } \\
27.6 \pm 1.7\end{array}$ & \\
\hline Rimonda et al. [21] & $\mathrm{RCT}$ & 70 & 70 & & & $\begin{array}{r}116.3 \pm 44 \text { vs } \\
114.8 \pm 47.6\end{array}$ & $\begin{array}{c}111.2 \pm 51.5 \text { vs } \\
107.9 \pm 42\end{array}$ \\
\hline Marcello et al. [25] & RCT & 52 & & 48 & & $\begin{array}{c}177 \pm 62 \text { vs } \\
186 \pm 70\end{array}$ & $\begin{array}{c}217 \pm 167 \text { vs } \\
231 \pm 166\end{array}$ \\
\hline Targarona et al. [22] & RCT & 15 & 12 & & 11 & $\begin{array}{l}110(70-210) \text { vs } 120 \\
(65-220) \text { vs } 180 \\
(90-210)\end{array}$ & $\begin{array}{l}100(0-450) \text { vs } 100 \\
(0-150) \text { vs } 200 \\
(0-350)\end{array}$ \\
\hline Heili et al. [31] & Retrospective & & 49 & 36 & & 170 vs 187 & 98 vs 95 \\
\hline
\end{tabular}

$R C T$ randomized controlled trial 
Campagnacci et al. [18] reported data in terms of mean and $p$ value but did not report standard deviations or standard error. In this case, following the indications mentioned in the Cochrane Handbook, the $t$ test was used to estimate the standard deviation. The $t$ test also was used for the Targarona et al. [22] study, in which only the median value and the $p$ value are reported.

\section{Operative time}

The time for dissection was significantly shorter with the use of EBVS than with the use of UE $(p=0.013)$. As shown in Graphic 1, the greatest differences in operative time between the evaluated instruments were reported by Takada et al. [19] and Targarona et al. [22] in favor of EBVS. A further subanalysis was performed excluding the Targarona study (which reported median values) to evaluate whether its inclusion influenced the final outcome. In this case, SMD changed from -0.72 to -0.67 , but the difference was always significant $(p=0.035)$.

Two studies $[19,21]$ reported all the necessary data for metaanalysis. In both series of Takada et al. [19], great differences in operating time between the evaluated instruments were observed. On the other hand, the study of Rimonda et al. [21] showed no significant difference between the compared instruments in terms of intra- or postoperative morbidity or operative time. The combined mean in this case was not statistically significant (Table 2; Graphic 2).

In conclusion, considering operative time, the metaanalysis showed a global effect favoring EBVS. However, when the two more complete series were considered $[19,21]$, no statistically significant difference was obtained.
Table 2 LigaSure versus ultrasonic energy: operating time

\begin{tabular}{lllrc}
\hline Study & \multicolumn{2}{l}{ SMD [95 \% CI] } & & \% Weight \\
\hline Takada 2 & -3.271 & -5.043 & -1.499 & 6.95 \\
Targarona & -1.043 & -1.859 & -0.226 & 14.61 \\
Takada & -4.385 & -6.391 & -2.379 & 5.86 \\
Campagnacci 3 & -0.230 & -0.906 & 0.446 & 16.11 \\
Campagnacci & -0.162 & -0.636 & 0.312 & 18.18 \\
Campagnacci 2 & -0.137 & -0.536 & 0.262 & 18.87 \\
Rimonda & 0.033 & -0.299 & 0.364 & 19.42 \\
D + L pooled SMD & -0.723 & -1.296 & -0.150 & 100.00 \\
\hline
\end{tabular}

Heterogeneity $\chi^{2}=34.30(d f=6) ; p=0.000$

$\mathrm{I}^{2}$ (variation in SMD attributable to heterogeneity) $=82.5 \%$

Estimate of between-study variance $\tau^{2}=0.4115$

Test of SMD $=0 ; z=2.47 ; p=0.013$

$S M D$ standardized mean difference, $C I$ confidence interval

Intraoperative blood loss

In the evaluation of this parameter, the study of Takada et al. [19] was excluded because it did not report data on blood loss. The analysis shows a significant difference in the combined mean of blood loss between the two instruments favoring EBVS (Tables 3, 4). However, the analysis in Graphic 3, clearly shows that the series of Campagnacci et al. [18] affected the global difference between the instruments and made it statistically significant (Graphic 3).

\section{Discussion}

The safety and efficacy of tissue dissection and vessel sealing in colorectal surgery still are a topic of major
Graphic 1 LigaSure versus ultracision energy: operative time

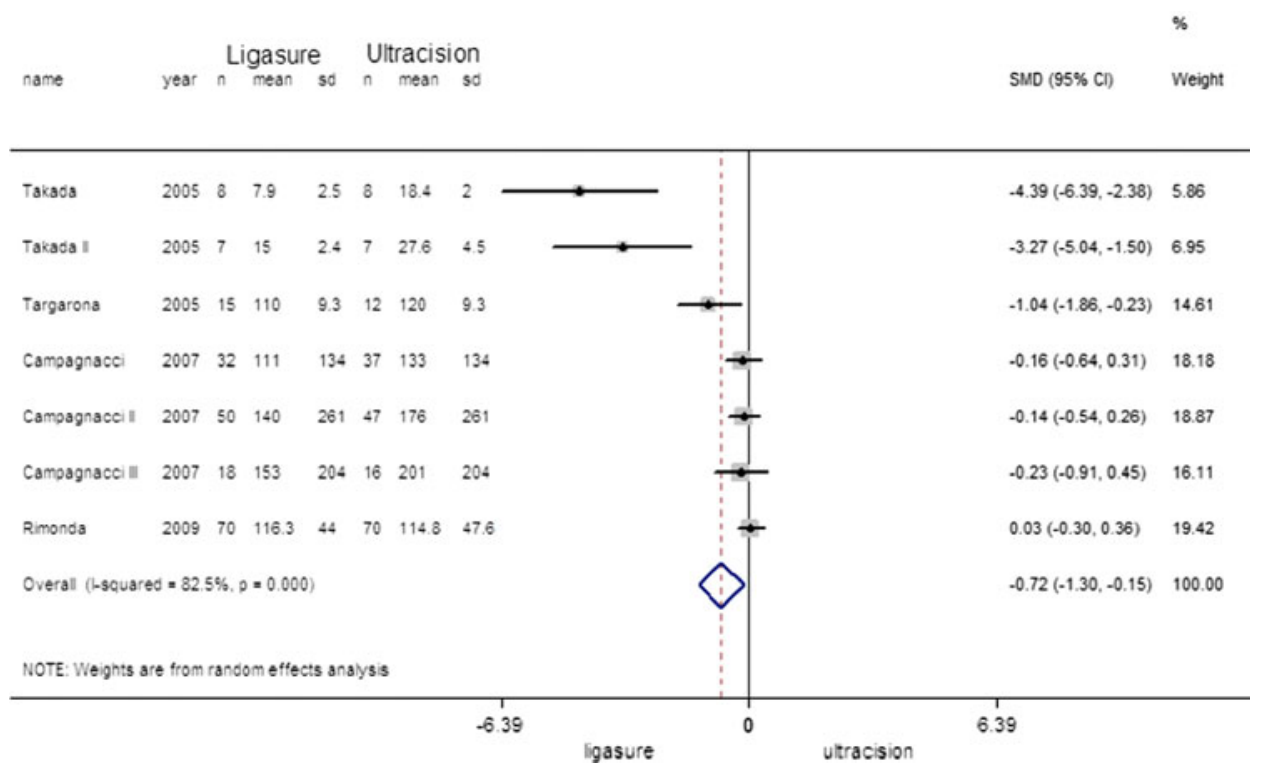


Graphic 2 LigaSure versus ultracision energy: operating time

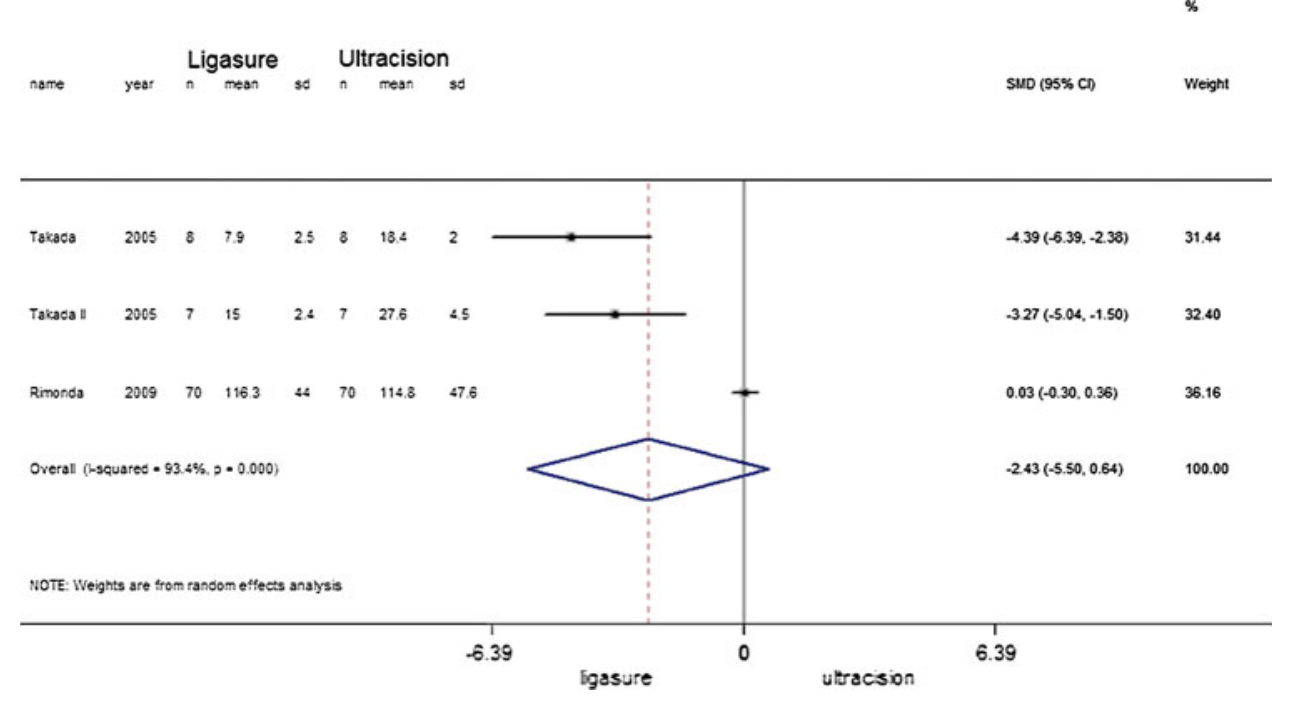

Table 3 LigaSure versus ultracision energy: intraoperative blood loss

\begin{tabular}{lrrrr}
\hline Study & \multicolumn{2}{c}{ SMD [95 \% CI] } & & \% Weight \\
\hline Takada 2 & -3.271 & -5.043 & -1.499 & 32.40 \\
Takada & -4.385 & -6.391 & -2.379 & 31.44 \\
Rimonda & 0.033 & -0.299 & 0.364 & 36.16 \\
D + L pooled SMD & -2.427 & -5.498 & 0.644 & 100.00 \\
\hline
\end{tabular}

Heterogeneity $\chi^{2}=30.15(d f=2) ; p=0.000$

$\mathrm{I}^{2}$ (variation in SMD attributable to heterogeneity) $=93.4 \%$

Estimate of between-study variance $\tau^{2}$ square $=6.7604$

Test of SMD $=0 ; z=1.55 ; p=0.121$

$S M D$ standardized mean difference, $C I$ confidence interval

Table 4 LigaSure versus ultracision, intraoperative blood loss, different studies

\begin{tabular}{lrrrr}
\hline Study & \multicolumn{2}{c}{ SMD [95 \% CI] } & & \% Weight \\
\hline Targarona & 0.000 & -0.759 & 0.759 & 16.17 \\
Campagnacci & -1.157 & -1.892 & -0.423 & 16.60 \\
Campagnacci & -0.822 & -1.315 & -0.328 & 20.97 \\
Campagnacci 2 & -0.751 & -1.163 & -0.338 & 22.44 \\
Rimonda & 0.070 & -0.262 & 0.401 & 23.82 \\
D + L pooled SMD & -0.516 & -1.001 & -0.031 & 100.00 \\
\hline
\end{tabular}

Heterogeneity $\chi^{2}=18.45(d f=4) ; p=0.001$

$\mathrm{I}^{2}$ (variation in SMD attributable to heterogeneity) $=78.3 \%$

Estimate of between-study variance $\tau^{2}=0.2284$

Test of SMD $=0 ; z=2.09 ; p=0.037$

$S M D$ standardized mean difference, $C I$ confidence interval

debate. Conventional monopolar electrosurgery is highly effective for simple dissection but has several drawbacks (i.e., severe scarring, risk of thermal injury, difficult hemostasis, and smoke production). Bipolar electrosurgery is safer, but the tip of the instrument does not aid dissection tasks, and it may induce severe local burning. To overcome these limitations, several multifunctional tools have been developed, the most popular of which are EBVS [8] and UE [9-11].

Ultrasonic dissection works at a temperature below $80{ }^{\circ} \mathrm{C}$ compared with $100{ }^{\circ} \mathrm{C}$ for electrosurgery. As a result, the risk of thermal damage to adjacent structures should be reduced. The ultrasonic energy induces protein denaturation by transfer of mechanical energy to the tissue, which is sufficient to break tertiary hydrogen bonds, and by generation of heat from internal cellular friction, which results from the high-frequency vibration of the tissue. As a result, the tissue dissection and the hemostasis are achieved.

Large vessels bleed when they are cut by the sharp edge of a scalpel but not when pressure is applied to them with the side of the blade and the blade is vibrated for a brief period (2-3 s). The Harmonic scalpel is able to coagulate vessels up to $5 \mathrm{~mm}$ in diameter.

The EBVS system is an electrosurgical technology that combines pressure and energy to create a seal. It applies a unique form of bipolar electrosurgery in combination with optimal pressure delivery by the instruments to fuse the vessel walls and create a permanent seal. The seal, created by melting the collagen and elastin in the vessel walls, can seal blood vessels up to $7 \mathrm{~mm}$ in diameter [9]. It does not rely on a proximal thrombus. The output is feedbackcontrolled so that a reliable seal is achieved in minimal time, independently of the type or amount of tissue in the jaws. The thermal spread is significantly less than with traditional bipolar systems and comparable with that of ultrasonic coagulation [23].

However, the assumption that the described devices significantly reduce the risk of collateral thermal injury was disproved by animal experimentation, which confirmed the 
Graphic 3 LigaSure versus ultracision energy: blood loss

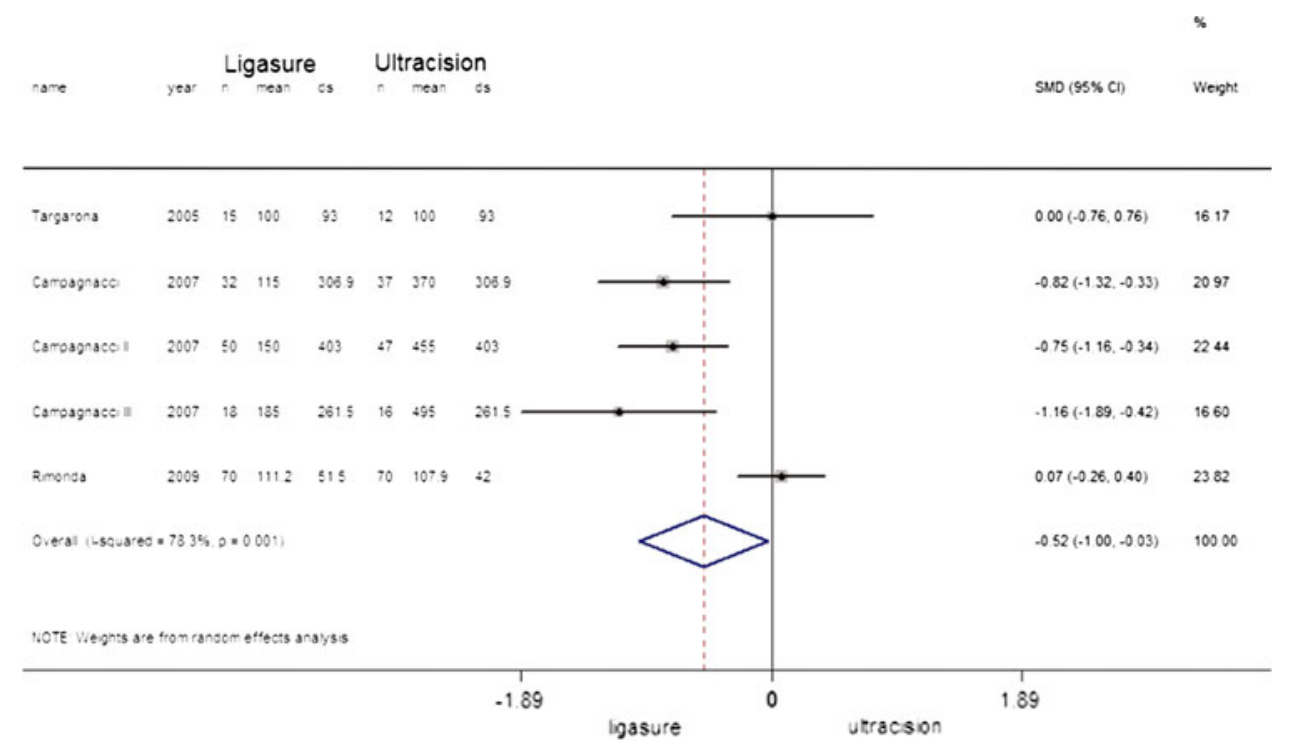

generation of very high temperatures at the instrument tip and thermal damage [11, 27-29]. Among the alternative energy sources, an innovation in tissue-selective separation/dissection using water jet could be the Erbejet 2 (ERBE USA, Inc., Georgia), which uses precise and gentle pressure rather than intense heat. This device drastically reduces unintentional destruction of healthy tissue, accidental burns, and poor visualization, all of which are common side effects of thermal/ultrasonic methods.

Nevertheless, although intra- and postoperative complications rates after laparoscopic colorectal surgery were not the object of this metaanalysis, no significant differences were reported in any of the trials published in the literature that compared EBVS/UE with conventional electrosurgery [20, 22, 24, 25]. The same conclusion was drawn by Macario et al. [30] despite several limitations in a metaanalysis assessing outcomes of EBVS versus other methods for hemostasis in patients submitted to different surgical procedures including hemorrhoidectomy, hysterectomy, thyroidectomy, and adrenalectomy.

A wide range of options currently are proposed for control of large vascular pedicles including staplers, clip appliers, suture ligature, and EBVS. For smaller vessels, UE may be used but is not currently recommended for division of the larger pedicles. The costs of these devices are significant, ranging from $\$ 100$ to $\$ 350$. Laparoscopic staplers and clip appliers require reloads, whereas EBVS may be used throughout a procedure without additional cost. However, no published randomized studies in laparoscopic colectomy have compared these devices in the division of vascular pedicles [30].

Although several studies have proved the safety and efficacy of both EBVS and UE, only a few have compared the two with statistical analysis, particularly in the critical field of colorectal laparoscopic surgery. Moreover, the heterogeneity of the studies published in the literature makes it difficult to compare the two instruments.

Earlier studies on the topic have shown different results. Most of them proved comparable advantages with the use of EBVS and UE devices, especially in difficult cases. Two of the studies $[18,19]$ tended to prove a slight advantage with the use of EBVS, although these studies had some statistical bias because they were not randomized. The study of Takada et al. [19] included a number of different procedures that were not standardized (e.g., transverse resections). Nevertheless, the authors concluded that EBVS had an advantage of $\sim 10-12 \mathrm{~min}$ in the mesocolon dissection and a 1:5 risk of rebleeding compared with UE.

Targarona et al. [22] reported reduced operating time and blood loss with EBVS and UE compared with electrosurgery for patients with colon disease requiring an elective segmental left-sided colon resection. However, the total number of patients was limited (38 patients), and the randomization process was not stated. Furthermore, endostaplers were used for vessel control in the UE group, whereas clips were used in the monopolar electrocautery scissors (MES) and EBVS groups.

More recently, the study of Campagnacci et al. [18] showed a 1:3 risk of intraoperative bleeding in favor of UE, with a slight advantage also in the dissection time of about $20 \mathrm{~min}$ for right hemicolectomies, $30 \mathrm{~min}$ for left hemicolectomies, and $50 \mathrm{~min}$ for anterior resection, although in all cases, the advantage was not statistically significant.

In addition for the retrospective design of the current study, which represents its major drawback, another criticism may lie in the fact that the experience gained with UE before the EBVS probably resulted in some advantages in terms of dexterity and operating time saving in the EBVS series. There also was a different technical step between the two groups favoring the EBVS (e.g., the titanium clips 
were used for all vessels in the UE but only for the inferior mesenteric artery in the EBVS patients), which may have had an effect on operating time.

Rimonda et al. [21], in an RCT with enough statistical power to demonstrate a difference of at least $20 \%$ in blood loss between the EBVS and UE devices, failed to show a clear advantage with use of the EBVS device over use of the UE device. The slight differences in favor of EBVS used during right hemicolectomies and in favor of UE used during left hemicolectomies and anterior resection did not reach statistical significance. The risk of intraoperative bleeding and postoperative rebleeding was similar in the two groups.

Through a prospective randomized study, Hubner et al. [20] compared MES, EBVS, and UCS in terms of dissection time, blood loss, safety, and costs for candidates of laparoscopic left colectomy. The median dissection time was significantly lower for both EBVS and UCS than for MES, mainly because of reduced instrument traffic. Blood loss also was less with both instruments than with MES, but the difference was not significant (125 vs. 50 vs. $50 \mathrm{ml}$ ). However, only 61 patients were randomized in the three arms of this study, so this sample may not have been sufficiently large to detect minor differences in the evaluated end points. Furthermore, the evaluated outcomes were presented as median and range and consequently could not be included in our metaanalysis.

The different study designs, the small number of enrolled patients with different evaluated outcomes, and the lack of a large number of RCTs increased the heterogeneity of our metaanalysis. Consequently, even if EBVS seems to be favored in terms of intraoperative blood loss and operative time, our findings should be interpreted with caution. A basic condition for any further research remains a clear definition of "operative time" (actual operative time? dissection time?) and "blood loss" (subjective appraisal? difference in hematocrit before and after surgery? number of perioperative blood transfusions? volume in the aspirator?) to ensure accurate and reproducible clinical outcomes. Also, a solid methodology for reporting RCTs according to the CONSORT statement should be guaranteed.

In conclusion, this metaanalysis indicates that EBVS is associated with better intraoperative results in terms of shorter operative time and less blood loss than UE in laparoscopic colorectal surgery. Nevertheless, more adequately designed RCTs with larger samples are required to confirm and enhance the results of this metaanalysis.

Disclosures Nicola Di Lorenzo, Luana Franceschilli, Marco Ettore Allaix, Anastasios Asimakopoulos, Pierpaolo Sileri, and Achille L. Gaspari have no conflicts of interest or financial ties to disclose.

\section{References}

1. Shin T, Rafferty JF (2010) Laparoscopy for benign colorectal diseases. Clin Colon Rectal Surg 23:42-50

2. Jayne DG, Thorpe HC, Copeland J, Quirke P, Brown JM, Guillou PJ (2010) Five-year follow-up of the Medical Research Council CLASICC trial of laparoscopically assisted versus open surgery for colorectal cancer. Br J Surg 97:1638-1645

3. Colon Cancer Laparoscopic or Open Resection Study Group, Buunen M, Veldkamp R, Hop WC, Kuhry E, Jeekel J, Haglind E, Påhlman L, Cuesta MA, Msika S, Morino M, Lacy A, Bonjer HJ (2009) Survival after laparoscopic surgery versus open surgery for colon cancer: long-term outcome of a randomised clinical trial. Lancet Oncol 10:44-52

4. Bennett CL, Stryker SJ, Ferreira MR, Adams J, Beart RW Jr (1997) The learning curve for laparoscopic colorectal surgery: preliminary results from a prospective analysis of 1,194 laparoscopic assisted colectomies. Arch Surg 132:41-44

5. Sardinha TC, Wexner SD (1998) Laparoscopy for inflammatory bowel disease: pros and cons. World J Surg 22:370-374

6. Nduka CC, Super PA, Monson JR, Darzi AW (1994) Cause and prevention of electrosurgical injuries in laparoscopy. J Am Coll Surg 179:161-170

7. Grosskinsky CM, Hulka JF (1995) Unipolar electrosurgery in operative laparoscopy: capacitance as a potential source of injury. J Reprod Med 45:549-552

8. Heniford BT, Matthews BD, Sing RF, Backus C, Pratt B, Greene FL (2001) Initial results with an electrothermal bipolar vessel sealer. Surg Endosc 15:799-801

9. Harold KL, Pollinger H, Matthews BD, Kercher KW, Sing RF, Heniford BT (2003) Comparison of ultrasonic energy, bipolar thermal energy, and vascular clips for the hemostasis of small-, medium-, and large-sized arteries. Surg Endosc 17:1228-1230

10. Amaral JF (1994) The experimental development of an ultrasonically activated scalpel for laparoscopic use. Surg Laparosc Endosc 4:92-99

11. Emam TA, Cuschieri A (2003) How safe is high-power ultrasonic dissection? Ann Surg 237:186-191

12. Siestes C, Eijsbouts QAJ, von Blomberg BM, Cuesta MA (2001) Ultrasonic energy vs monopolar electrosurgery in laparoscopic cholecystectomy: influence on the postoperative systemic immune response. Surg Endosc 15:69-71

13. Layock WS, Trus TL, Hunter JG (1996) New technology for the division of host gastric vessels during laparoscopic Nissen fundoplication: a prospective randomized trial. Surg Endosc 10:71-73

14. Pautler SE, Choyke P, Pavlovich CP, Daryanani K, Walther MM (2002) Intraoperative ultrasound aids in dissection during laparoscopic partial adrenalectomy. J Urol 168:1352-1355

15. Foschi D, Cellerino P, Corsi F, Taidelli T, Morandi E, Rizzi A, Trabucchi E (2002) The mechanism of blood vessel closure in humans by the application of ultrasonic energy. Surg Endosc $16: 814-819$

16. LeeWJ Chen TC, Lai IR, Huang MT, Wang W (2003) Randomized clinical trial of LigaSure versus conventional surgery for extended gastric cancer resection. Br J Surg 90:1493-1496

17. Moher D, Liberati A, Tetzlaff J, Altman DG, The PRISMA Group (2009) Preferred reporting items for systematic reviews and meta-analyses: The PRISMA Statement. PLoS Med 6(7):e1000097

18. Campagnacci R, de Sanctis A, Baldarelli M, Rimini M, Lezoche G, Guerrieri M (2007) Electrothermal bipolar vessel sealing device vs ultrasonic coagulating shears in laparoscopic colectomies: a comparative study. Surg Endosc 21:1526-1531 
19. Takada M, Ichihara T, Kuroda Y (2005) Comparative study of electrothermal bipolar vessel sealer and ultrasonic coagulating shears in laparoscopic colectomy. Surg Endosc 19:226-228

20. Hubner M, Demartines N, Muller S, Dindo D, Clavien P-A, Hahnloser D (2008) Prospective randomized study of monopolar scissors, bipolar vessel sealer, and ultrasonic shears in laparoscopic colorectal surgery. Br J Surg 95:1098-1104

21. Rimonda R, Arezzo A, Garrone C, Allaix ME, Giraudo G, Morino M (2009) Electrothermal bipolar vessel sealing system vs harmonic scalpel in colorectal laparoscopic surgery: a prospective, randomized study. Dis Colon Rectum 52:657-661

22. Targarona EM, Balague C, Marin J, Neto RB, Martinez C, Garriga J et al (2005) Energy sources for laparoscopic colectomy: a prospective randomized comparison of conventional electrosurgery, bipolar computer-controlled electrosurgery, and ultrasonic dissection: operative outcome and costs analysis. Surg Innov 12:339-344

23. Diamantis T, Kontos M, Arvelakis A, Syroukis S, Koronarchis D, Papalois A, Agapitos E, Bastounis E, Lazaris AC (2006) Comparison of monopolar electrocoagulation, bipolar electrocoagulation, Ultracision, and LigaSure. Surg Today 36(10):908-913

24. Morino M, Rimonda R, Allaix ME, Giraudo G, Garrone C (2005) Ultrasonic versus standard electric dissection in laparoscopic colorectal surgery: a prospective randomized clinical trial. Ann Surg 242:897-901

25. Marcello PW, Roberts PL, Rusin LC, Holubkov R, Schoetz DJ (2006) Vascular pedicle ligation techniques during laparoscopic colectomy: a prospective randomized trial. Surg Endosc 20:263-269

26. Hubner M, Hahnloser D, Hetzer F, Muller MK, Clavien PA, Demartines N (2007) A prospective randomized comparison of two instruments for dissection and vessel sealing in laparoscopic colorectal surgery. Surg Endosc 21:592-594

27. Kinoshita T, Kanehira E, Omura K, Kawakami K, Watanabe Y (1999) Experimental study on heat production by a $23.5-\mathrm{kHz}$ ultrasonically activated device for endoscopic surgery. Surg Endosc 13:621-625

28. Kim FJ, Chammas MF Jr, Gewehr E, Morihisa M, Caldas F, Hayacibara E, Baptistussi M, Meyer F, Martins AC (2008) Temperature safety profile of laparoscopic devices: harmonic ACE (ACE), LigaSure V (LV), and plasma trisector (PT). Surg Endosc 22:1464-1469

29. Song C, Tang B, Campbell PA, Cuschieri A (2009) Thermal spread and heat absorbance differences between open and laparoscopic surgeries during energized dissections by electrosurgical instruments. Surg Endosc 23:2480-2487

30. Macario A, Dexter F, Sypal J, Cosgriff N, Heniford BT (2008) Operative time and other outcomes of the electrothermal bipolar vessel sealing system (LigaSure TM) versus other methods for surgical hemostasis: a meta-analysis. Surg Innov 15:284-291

31. Heili MJ, Flowers SA, Fowler DL (1999) Laparoscopic-assisted colectomy: a comparison of dissection techniques. JSLS 3:27-31 